\title{
Behavior of reinforced concrete slender rectangular columns under uniaxial loading
}

\author{
Bassman Muhammad* \\ Building and Construction Engineering Department, University of Technology, Baghdad, Iraq
}

\begin{abstract}
Two proposed formulae are presented to obtain the reinforced concrete slender column capacity. Reinforced concrete slender columns are used more nowadays than in the past 30 years because of development of engineering materials. Structural engineers that adopted the ACI 318M Code know that the design of this type of columns is more tedious than short ones. This research proposes two formulae that reflect the ultimate strength of cross section of slender columns, one for the axial and the second for the bending moment. Case study of 656250 columns is generated to cover most variable properties of columns, analyzed using MATLAB (R2017a) Program to obtain the ultimate strength of cross section then compared to the strength of slender columns.
\end{abstract}

Notations:

$\mathrm{h}_{\mathrm{x}}(\mathrm{h})=$ The cross sectional column side in the direction parallel with the eccentricity $\left(\mathrm{e}_{\mathrm{x}}\right), \mathrm{mm}$.

$\mathrm{h}_{\mathrm{y}}(\mathrm{b})=$ The cross sectional column side in the direction perpendicular to the eccentricity $\left(\mathrm{e}_{\mathrm{x}}\right), \mathrm{mm}$.

$f^{\prime}=$

$\alpha_{1} \quad=$

$f_{\mathrm{y}} \quad=$

$\mathrm{A}_{\mathrm{s}} \quad=$

$\mathrm{P} \quad=$

$\Gamma \quad=$

$\beta_{1} \quad=$

$\mathrm{C}=$

$\mathrm{e}_{\mathrm{x}} \quad=$

$\beta_{\mathrm{d}} \quad=$

$\mathrm{k} \ell=$

$\mathrm{R} \quad=$

$\varepsilon_{\mathrm{cu}} \quad=$

$\mathrm{P}_{\mathrm{o}} \quad=$

$\varnothing_{\mathrm{s}} \quad=$

$\mathrm{P}_{\mathrm{c}}, \mathrm{P}_{\mathrm{s}}=$

$\mathrm{M}_{\mathrm{c}}, \mathrm{M}_{\mathrm{s}}=$ Specified compressive strength of standard cylinder concrete at 28 days, MPa. Correction intensity cylinder compressive strength, 0.85 .

Specified yield strength for longitudinal steel reinforcement, MPa.

Total area of the longitudinal column reinforcement, $\mathrm{mm}^{2}$.

Column total gross steel ratio, $\left(\mathrm{A}_{\mathrm{s}} / \mathrm{A}_{\mathrm{g}}\right)$.

End steel lever arm column cross sectional factor.

Equivalent relating rectangular compressive stress block to depth of neutral axis.

The neutral compression axis depth, mm.

The applied eccentricity of the load about $\mathrm{x}$ - axis, $\mathrm{mm}$.

Creep reduction factor of the column.

Effective length of the column, $\mathrm{mm}$.

Column cross section radius of gyration $=0.3 \mathrm{~h}, \mathrm{~mm}$.

The strain limit of extreme concrete fiber in compression $=0.003 \mathrm{~mm} / \mathrm{mm}$.

The ultimate concentric axial load capacity, $\mathrm{kN}$.

ACI 318M-14 Euler Load factor of safety, 0.75.

Cross Sectional capacity for cross section and column ultimate axial load capacity (for slender column), respectively, $(\mathrm{kN})$.

Cross Sectional bending moment capacity for cross section and column ultimate bending moment capacity (for slender column), respectively, (kN.m).

\footnotetext{
*Corresponding author: bassman.riyadh@gmail.com
} 


\section{Introduction}

In last decades, the high rise buildings, stronger materials tend to construct taller buildings with less cross sectional element.[1]

The slender column is an important element in any structural building and its calculations tend to be tedious because of its properties like the flexural rigidity (EI), Euler load buckling $\left(\mathrm{P}_{\mathrm{cr}}\right)$ to obtain the magnification bending moment factor ( $\delta$ ). In 1993, MacGregor[4] proposed a new method for analysis of slender columns, he developed the magnification factor $(\delta)$ and proposed magnifications of moments applied on the columns for sway then magnify the overall sway and nonsway.

This provision was adopted in the ACI 318M-95[4] and is still accepted up to now. Many researchers studied this method, compared with experimental columns results, such as Lloyd and Rangan[5] and found good correlation between results.

\section{Research significance}

Two proposed formulae were obtained using statistical nonlinear best fit regression analysis for 656250 slender columns. These formulae are derived statistically to obtain the strength of the slender column from the strength of its cross section.

Also, study of the behavior of slender columns for all its mechanical and geometrical properties are presented.

\section{Strength of slender columns}

The ACI 318M-14[2] provides magnification method for analysis and design of the slender columns. To study this method, 656250 columns were generalized with the following parameter properties:

- $f^{\prime}{ }_{\mathrm{c}}=20$ to $80 \mathrm{MPa}$; (10 MPa increments).

- $f_{\mathrm{y}}=200$ to $600 \mathrm{MPa} ;(100 \mathrm{MPa}$ increments).

- $\quad(\mathrm{e} / \mathrm{h})_{\mathrm{x}}=0.1$ to $5 ;(0.1$ increments $)$.

- $\gamma=0.5$ to $0.9 ;(0.1$ increments $)$.

- $\rho=0.01$ to $0.05 ;(0.01$ increments $)$.

- $\mathrm{k} \ell / \mathrm{r}=20$ to $60 ;(10$ increments).

- $\beta_{\mathrm{d}}=0$ to $0.4 ;$ (0.2 increments).

In this research, constant values of some parameters according to the ACI $318 \mathrm{M}-14$ depended. The strain limit of extreme concrete fiber in compression $\left(\varepsilon_{\mathrm{cu}}\right)=$ $0.003 \mathrm{~mm} / \mathrm{mm}$; Correction intensity cylinder compressive strength $\left(\alpha_{1}\right)=0.85$; the modulus of elasticity of reinforcement $\left(E_{s}\right)=2 \times 10^{5} \mathrm{MPa}$; the strength reduction stability factor $\left(\varnothing_{\mathrm{s}}\right)=0.75$.

MATLAB (R2017a) was used to generate and analyze and the statistical results were computed in an incremental process program. The ratios between the ultimate strength of axial load for the slender column to the ultimate strength of its cross section is shown in Fig. (1).

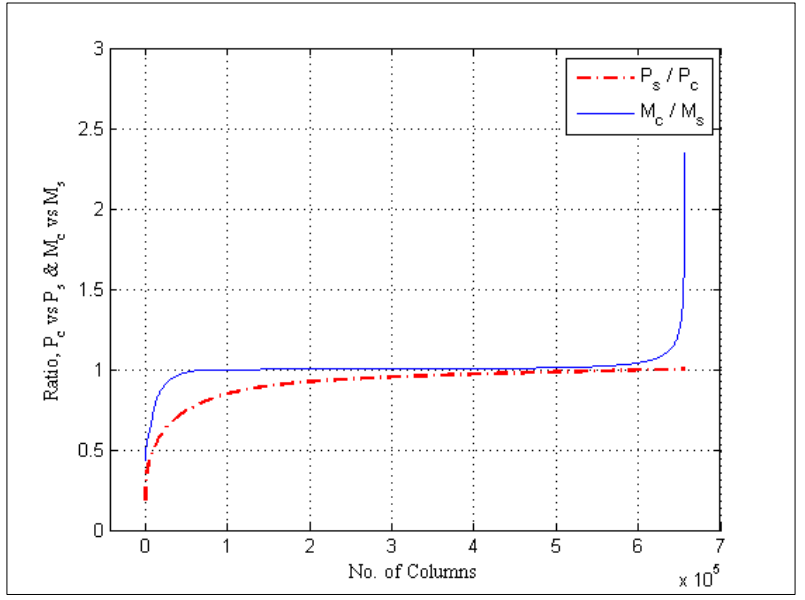

Fig. 1. The relation between ultimate strength of the column vs its cross section for generated Columns.

Noting that; the minimum and maximum ratios between $\left(\mathrm{P}_{\mathrm{s}} / \mathrm{P}_{\mathrm{c}}\right)$ are $0.1922 ; 1.0000$; and the minimum and maximum ratios between $\left(\mathrm{M}_{\mathrm{c}} / \mathrm{M}_{\mathrm{s}}\right)$ are 0.4300; 2.3442 .

The minimum ultimate load reduction for the axial force (column number $=562515)$ has the following properties:

$$
\begin{array}{ll}
f^{\prime}{ }_{\mathrm{c}} & =80(\mathrm{MPa}) \\
f_{\mathrm{y}} & =200(\mathrm{MPa}) \\
(\mathrm{e} / \mathrm{h})_{\mathrm{x}} & =0.1 \\
\gamma_{\mathrm{x}} & =0.5 \\
\rho_{\mathrm{x}} & =0.01 \\
(\mathrm{k} \ell / \mathrm{r})_{\mathrm{x}} & =60 \\
\beta_{\mathrm{d}} & =0.4 \\
\mathrm{P}_{\mathrm{s}} / \mathrm{P}_{\mathrm{c}} & =0.192 \\
\mathrm{M}_{\mathrm{c}} / \mathrm{M}_{\mathrm{s}} & =1.098 \\
\mathrm{P}_{\mathrm{n}} / f_{\mathrm{c}} \mathrm{b} \mathrm{h} & =0.691 \\
\rho f_{\mathrm{y}} / f^{\prime} \mathrm{c} & =0.025 \\
\mathrm{P} / \mathrm{P}_{\mathrm{o}} & =0.798
\end{array}
$$

In addition, the ratios between cross sectional bending moment and the column moment stagger above and below unity.

\section{MATLAB (R2017a) program}

Incremental of the compression zone technique was used to solve each column twice, first for the cross section capacity then second for the slender column with full geometrical and mechanical properties. The tolerance dependence in solution of each column was 0.001 .

A huge results data for input and output (array's size that treatment is 1312500 by 26). Therefore, statistical and graphical methods were used to study these results.

The ACI $318 \mathrm{M}-14$ cross sections and magnification columns procedure was used in the programme. 


\section{Nonlinear regression for the axial load $\left(P_{n}\right)$}

A nonlinear curve fitting programed in MATLAB (R2017a) was used to obtain a compatible representation with the true column behavior. The variables studied with many equations to obtain a good relation with the curve shown in Fig. (2), these independent variables are:

1. $\mathrm{P}_{\mathrm{n}} / f^{\prime}{ }_{\mathrm{c}} \mathrm{b} \mathrm{h}$;

2. $\rho f_{\mathrm{y}} / f^{\prime}$;

3. $(\mathrm{e} / \mathrm{h})$;

4. $(\mathrm{k} \ell / \mathrm{r})$

5. $\mathrm{P} / \mathrm{P}_{\mathrm{o}}$;

6. $\beta_{\mathrm{d}} ;$ and

7. $\gamma$.

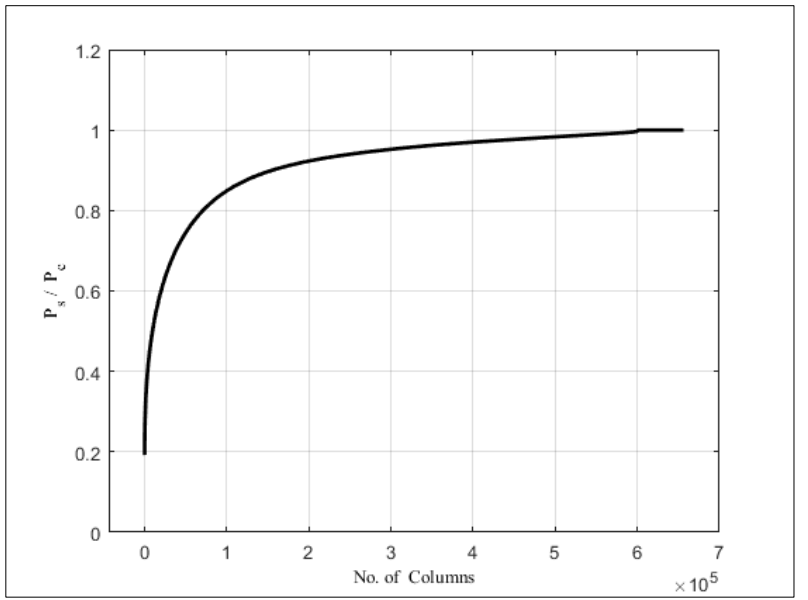

Fig. 2. The relation between ultimate strength of the axial load columns vs its cross section capacity for generated Columns.

Statistically, Eq. (1) is obtained to represent $R_{p}$.

$$
\begin{gathered}
R_{p}=0.872+\frac{0.8 P_{n}}{f_{c}^{\prime} b h}-\frac{2 \rho f_{y}}{30 f_{c}^{\prime}}+\frac{e}{42 h}-\frac{P_{n}}{5 P_{o}} \sqrt{\frac{k \ell}{r}} \\
-\frac{3 \beta_{d}}{55}+\frac{\gamma}{14.8} \\
\leq 1.0
\end{gathered}
$$

In which; $\mathrm{R}_{\mathrm{p}}=\mathrm{P}_{\mathrm{s}} / \mathrm{P}_{\mathrm{c}} ; \mathrm{P}_{\mathrm{n}}$ is the column capacity for cross section and $\mathrm{P}_{\mathrm{o}}$ is the nominal axial strength at zero eccentricity for the cross section, $\mathrm{P}_{\mathrm{o}}=0.85 f^{\prime}{ }_{\mathrm{c}}\left(\mathrm{A}_{\mathrm{g}}-\mathrm{A}_{\mathrm{st}}\right)$ $+f_{\mathrm{y}} \mathrm{A}_{\mathrm{st}}$.

Graphically, this equation has a good accuracy with the axial load behavior. The statistical results are:

Multiple $\mathrm{R}=0.875$.

R Square $=0.76$.

Adjusted R Square $=16.86$.

Mean values $=0.92$.

Coefficient of variation $=8.16 \%$.

Fig. (3) shows the relation between the results of $\left(\mathrm{P}_{\mathrm{s}} / \mathrm{P}_{\mathrm{c}}\right)$ vs the proposed Eq. (1).

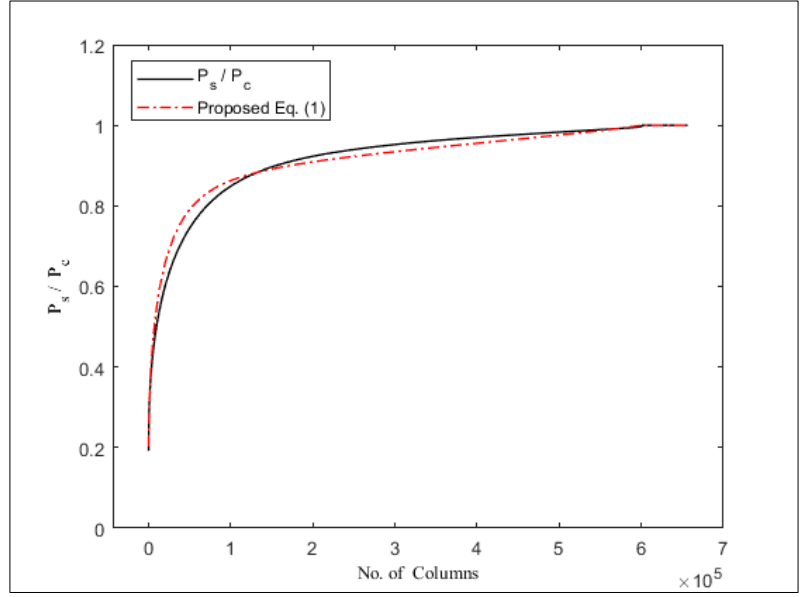

Fig. 3. Comparison between the proposed load formulae with the exact results.

\section{Nonlinear regression for the bending moment $\left(M_{n}\right)$}

Again, nonlinear curve fitting was programmed using MATLAB (R2017a) to best fit the behavior of column in bending moment. This behavior is divided into three parts to obtain statistical results, this division was decided because the relation between ultimate strength of the bending moment for the columns vs its cross section moment capacity for generated columns behaves in three parts - semi-vertical, semi-horizontal and semivertical, Fig. (4). Each part of the curve was analyzed separately. The statistical results (squared $r$ ) show no valuable differences between these three parts.

For this reason, one formula is proposed to formulate the relation between the cross sectional bending capacity and the bending capacity of slender ones. To make the formula practical for this research, the same independent variables were intentionally used in Eq. (1).

From Fig. (4), $R_{m}$ (which equals $M_{c} / M_{s}$ ) is safe when the inspected value is less than the real ratio, so that, to make the formula of bending moment prediction more accurate, statistical results were made for 600000 columns only, i.e. the third part of Fig. (4) was excluded from the statistical analysis. The rest of the columns (56250 columns makes about $8.5 \%$ from the total columns studied) have no major effect on the results.

From some trials of regression analyses, Eq. (2) is selected to predict the slender bending moment capacity of the slender columns. 


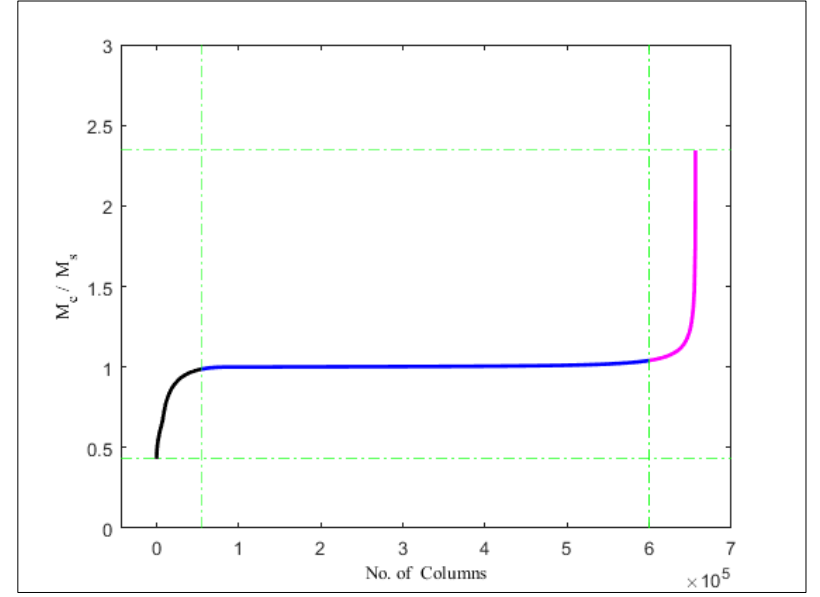

Fig. 4. The relation between ultimate strength of the bending moment for the columns vs its cross section moment capacity for generated columns.

$R_{m}$

$=1.05+\frac{P_{n}}{74 f_{c}^{\prime} b h}+\frac{\rho f_{y}}{52 f_{c}^{\prime}}-\frac{e}{70 h}-\frac{2 P_{n}}{31 P_{o}} \sqrt{\frac{k \ell}{r}}$

$+\frac{\gamma}{50}$

$R_{m}=M_{c} / M_{s}$ and $P_{n}$ is the column capacity for cross section.

The statistical results of Eq. (2) are:

Multiple $\mathrm{R}=0.885$.

R Square $=0.784$.

Adjusted R Square $=8.503$.

Mean values $=0.993$.

Coefficient of variation $=3.659 \%$.

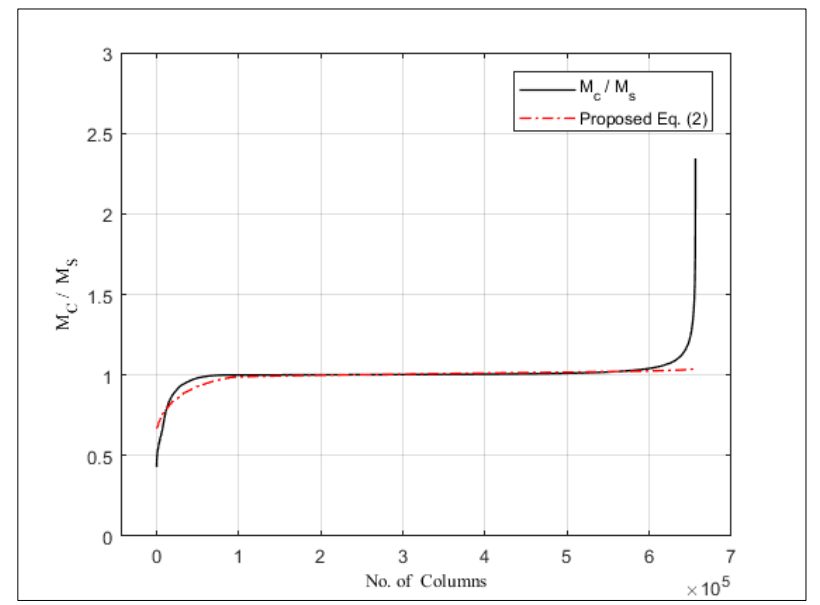

Fig. 5. Comparison between the proposed bending moment formulae with the exact results.

From Fig. (5), it can be seen that the proposed formula for bending moment capacity of the column has a good representation of the real behavior. Note: the last part (less than $8 \%$ of the total number of studied columns) predict a conservative value of a ratio equals 2.101 , since the prediction is less than these analyzed columns. Columns under large eccentricity, results a mall axial strength and large moment capacity, especially when the column steel force is small in value $\left(\mathrm{A}_{\mathrm{s}} f_{\mathrm{y}}\right.$ is small) with stronger concrete compressive strength (large $f^{\prime}{ }_{\mathrm{c}}$ value).

\section{Conclusions}

A theoretical investigation for $656250 \mathrm{RC}$ slender columns with various geometrical and mechanical properties analyzed according to the ACI $318 \mathrm{M}-14$, two formulae are proposed in this research; Eq. (1) and Eq. (2). For all columns, the ultimate axial strength was less than the cross sectional ultimate strength, the results show that these ratios ranged between $(0.1922-1.0)$. While for bending moments ultimate strength the ratios were scattered above and below 1.0, the ratios between the cross sectional bending moment to the column bending moment strength were between $(0.43-2.3442)$.

Design columns using these proposed equations are simpler using the interaction diagram by calculating the mechanical properties of columns, then obtaining the factors $R_{p}$ and $R_{m}$ and finally obtaining the required results according to the new load values $\left(R_{p} \times P_{n}\right.$ and $M_{n}$ / $\mathrm{R}_{\mathrm{m}}$ ).

\section{References}

1. J. Wight, J. MacGregor, Rein. Con. Mech. and Design, Pearson Edu., Inc., Upper Saddle River, New Jersey (2012)

2. ACI $318 \mathrm{M}-14$ and ACI 318RM-14, Detroit (2014)

3. J. MacGregor, ACI St. J. 90, 3, 302-309, MayJune (1993)

4. ACI 318-95 and ACI 318R-95, Detroit (1995)

5. N. A. Lloyd, B. V. Rangan, ACI St. J, 93, 6, 631-638, Nov. - Dec. (1996)

\section{Appendix (Numerical Example):}

For a RC column $(600 \times 800) \mathrm{mm} ; f^{\prime}{ }_{\mathrm{c}}=35 \mathrm{MPa} ; f_{\mathrm{y}}=400$ $\mathrm{MPa}$; total longitudinal steel area $\left(\mathrm{A}_{\mathrm{st}}\right)=6000 \mathrm{~mm}^{2}\left(\rho_{\mathrm{s}}=\right.$ $0.0125) ; \gamma=0.8 ; \mathrm{e}_{\mathrm{x}}=240 \mathrm{~mm}$ (i.e. $\mathrm{e}_{\mathrm{x}} / \mathrm{h}=240 / 800=$ $0.3)$; effective length $\left(\ell_{\mathrm{u}}\right)=7.2 \mathrm{~m}\left(\mathrm{k} \ell_{\mathrm{u}} / \mathrm{r}=30\right)$ and the creep factor $\left(\beta_{\mathrm{d}}\right)=0.4$.

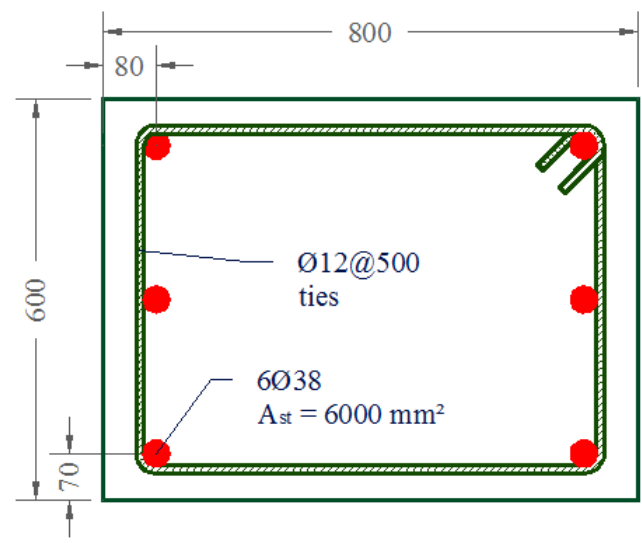


Fig. A-1. The cross section of the column

According to the ACI $318 \mathrm{M}-14$, the ultimate strength of the column is as follows: (note that the nominal cross section capacity can be obtained using any interaction diagram instead of manual iteration method).

\section{Part I - Cross Sectional Analysis (short column):}

After some trials; the compression depth (c) $=538.91$ $\mathrm{mm}$; therefore, $\mathrm{P}_{\mathrm{n}}=8201.53 \mathrm{kN}$ and $\mathrm{M}_{\mathrm{n}}=1968.3 \mathrm{kN}$.m.

\section{Part II - Slender Column Analysis:}

After some trials; the compression depth (c) $=457.88$ $\mathrm{mm}$; therefore, $\mathrm{P}_{\mathrm{n}}=6618.81 \mathrm{kN}$ and $\mathrm{M}_{\mathrm{n}}=2103.05$ kN.m. The total eccentricity $\left(\mathrm{e}_{\mathrm{x}}\right)=317.74 \mathrm{~mm}$ (i.e. $\delta=$ 1.324).

\section{Therefore:}

$\mathrm{R}_{\mathrm{p} \text { ACI 318M-14 }}=\mathrm{P}_{\mathrm{n} \text { slender }} / \mathrm{P}_{\mathrm{n} \text { short }}=6618.81 / 8201.53=$ 0.807 .

$\mathrm{R}_{\mathrm{m} \text { ACI 318M-14 }}=\mathrm{M}_{\mathrm{n} \text { short }} / \mathrm{M}_{\mathrm{n} \text { slender }}=1968.3 / 2103.05=$ 0.936 .

\section{Part III - Proposed Equations of this Research:}

$\mathrm{P}_{\text {no }}=[0.85 \times 35(800 \times 600-6000)+400 \times 6000] \times 10^{-3}=$ $16501.5 \mathrm{kN}$.

From Eq. (1),

$R_{p}=0.872+\frac{0.8 P_{n}}{f_{c}^{\prime} b h}-\frac{2 \rho f_{y}}{30 f_{c}^{\prime}}+\frac{e}{42 h}-\frac{P_{n}}{5 P_{o}} \sqrt{\frac{k \ell}{r}}-\frac{3 \beta_{d}}{55}+\frac{\gamma}{14.8}$

$\mathrm{R}_{\mathrm{p}}=\mathrm{P}_{\mathrm{s}} / \mathrm{P}_{\mathrm{c}}=0.872+0.8 \times\left\{8201.53 \times 10^{3} /(35 \times 600 \times\right.$ $800)\}-2 \times 0.0125 \times 400 /(30 \times 35)+0.3 / 42-8201.53$ $/(5 \times 16501.5) \times(30)^{0.5}-3 \times 0.4 / 55+0.8 / 14.8$

$\mathrm{R}_{\mathrm{p}}=0.751 .\left(\mathrm{R}_{\mathrm{p}} \leq 1\right)$.

From Eq. (2),

$R_{m}=1.05+\frac{P_{n}}{74 f_{c}^{\prime} b h}+\frac{\rho f_{y}}{52 f_{c}^{\prime}}-\frac{e}{70 h}-\frac{2 P_{n}}{31 P_{o}} \sqrt{\frac{k \ell}{r}}+\frac{\gamma}{50}$

$\mathrm{R}_{\mathrm{m}}=\mathrm{M}_{\mathrm{c}} / \mathrm{M}_{\mathrm{s}}=1.05+\left\{8201.53 \times 10^{3} /(74 \times 35 \times 600 \times\right.$ $800)\}+0.0125 \times 400 /(52 \times 35)-0.3 / 70-2 \times$ $8201.53 /(31 \times 16501.5) \times(30)^{0.5}+0.8 / 50$

$\mathrm{R}_{\mathrm{m}}=0.895$.

Tabulated the results (Table (A.1) and comparing with the ACI $318 \mathrm{M}-14$ results, it is shown that the results was a good prediction for the ultimate strength capacity.

Table A.1. Numerical Example Results

\begin{tabular}{|c|c|c|c|}
\hline & ACI 318M-14 & Proposed & Diff \% \\
\hline $\mathrm{R}_{\mathrm{p}}$ & 0.807 & 0.751 & $93 \%$ \\
\hline $\mathrm{R}_{\mathrm{m}}$ & 0.936 & 0.895 & $96 \%$ \\
\hline
\end{tabular}

From Table A.1, $\mathrm{P}_{\mathrm{n}}$ predicted for the slender column $=0.751 \times 8201.53=6159.35 \mathrm{kN}\left(\mathrm{P}_{\mathrm{n}^{-} \mathrm{ACI}} 318 \mathrm{M}-14\right.$ slender $=$ $6618.81 \mathrm{kN}$ - accuracy $=93.1 \%)) . \mathrm{M}_{\mathrm{n}}$ predicted for the slender column $=1968.3 / 0.895=2200 \mathrm{kN} . \mathrm{m}\left(\mathrm{M}_{\mathrm{n}}{ }^{-}\right.$ACI $318 \mathrm{M}-14$ slender $=2103.05 \mathrm{kN} \cdot \mathrm{m}-$ accuracy $=95.6 \%$ ). 